\title{
Research
}

\section{Prevention of hospital-acquired thrombosis from a primary care perspective:}

\author{
a qualitative study
}

\begin{abstract}
\section{Background}

Although there is considerable risk for patients from hospital-acquired thrombosis (HAT), current systems for reducing this risk appear inefficient and have focused predominantly on secondary care, leaving the role of primary care underexplored, despite the onset of HAT often occurring post-discharge.
\end{abstract}

\section{Aim}

To gain an understanding of the perspectives of primary care clinicians on their contribution to the prevention of HAT. Their current role, perceptions of patient awareness, the barriers to better care, and suggestions for how these may be overcome were discussed.

\section{Design and setting}

Qualitative study using semi-structured interviews in Oxfordshire and South Birmingham, England.

\section{Method}

Semi-structured telephone interviews with clinicians working at practices of a variety of size, socioeconomic status, and geographical location.

\section{Results}

A number of factors that influenced the management of HAT emerged, including patient characteristics, a lack of clarity of responsibility, limited communication and poor coordination, and the constraints of limited practice resources. Suggestions for improving the current system include a broader role for primary care supported by appropriate training and the requisite funding.

\section{Conclusion}

The role of primary care remains limited, despite being ideally positioned to either raise patient awareness before admission or support patient adherence to the thromboprophylaxis regimen prescribed in hospital. This situation may begin to be addressed by more robust lines of communication between secondary and primary care and by providing more consistent training for primary care staff. In turn, this relies on the allocation of appropriate funds to allow practices to meet the increased demand on their time and resources.

\section{Keywords}

prevention and control; primary health care; qualitative research; thrombosis.

\section{INTRODUCTION}

Hospital-acquired thrombosis (HAT) is a substantial healthcare problem resulting in significant mortality, morbidity, and economic cost. ${ }^{1,2}$ Recent estimates put the figures for hospital deaths from venous thromboembolism (VTE) in England and Wales in excess of $34000^{3}$ out of some 16 million admissions, ${ }^{4}$ although the introduction of the VTE risk assessment tool has led to a reduction in these numbers. It is a disorder that can occur across race, ethnicity, age group, and sex, with many of the known risk factors, such as advanced age, immobility, surgery, and obesity, on the increase. HAT can occur up to 90 days after admission, ${ }^{6}$ yet, to date, much of the focus on preventing HAT has fallen on the secondary care environment and there is little to no understanding of the role of primary care. However, a recent study that incorporated primary care data found that over $50 \%$ of deaths from VTE occurred after hospital discharge.?

This risk of developing HAT is influenced by the specific medical condition of the patient $^{8}$ and thromboprophylaxis has been shown to reduce the risk of VTE by $75 \%$ in surgical patients ${ }^{9}$ and by around $50 \%$ in medical patients. ${ }^{9.10}$

Current UK guidelines for preventing HAT ${ }^{11}$ (Figure 1) recommend using the Department of Health's risk assessment tool ${ }^{12}$ to inform the prescription of the appropriate thromboprophylaxis. ${ }^{13}$ The

I Litchfield, MSc, PhD, clinical lead, Institute of Applied Health Research; D Fitzmaurice, MD FRCGP, clinical lead, Primary Care Clinical Sciences; P Apenteng, MPhil, research fellow; S Greenfield, MA, PhD, professor of medical sociology, College of Medical and Dental Sciences, University of Birmingham, Edgbaston. S Harrison, BSc, ClinPsyD, research officer; $\mathbf{C}$ Heneghan, MA, DPhil, MRCGP, professor of evidence based medicine; A Ward, PhD, director of postgraduate studies, Nuffield Department of Primary Care Health Sciences, University of Oxford, Oxford. risk assessment tool uses factors, such as significant comorbidity, age, and pregnancy, alongside the risks associated with hospital admissions, such as reduced mobility for $>3$ days or undergoing surgery that lasts $>60$ minutes. The prophylaxis that is recommended consists of mechanical devices, such as antiembolism stockings, often used in combination with a pharmacological element including low molecular weight heparin (LMWH), sometimes prescribed for several months following surgery. ${ }^{11}$ Previous research abroad has indicated that non-adherence to guidelines is an issue for both physicians ${ }^{14}$ and patients. ${ }^{15,16}$ There is some evidence of similar issues of adherence among patients in the UK, ${ }^{17}$ with some reporting adherence to LMWHs as low as $23 \% .^{18}$ The guidelines also stipulate a supporting role for GPs, based on their notification of when patients are discharged and the prophylaxis prescribed. This type of communication between care settings is known to be problematic, ${ }^{19-23}$ leaving patients vulnerable to adverse events following discharge, ${ }^{24-29}$ and the role performed by primary care being unclear.

If primary care is to contribute more effectively to the prevention of HAT, then a better understanding of its current role and of the factors that influence this role is required. The ExPeKT study was designed to explore existing knowledge of thromboprophylaxis among patients,

\section{Address for correspondence}

lan Litchfield, Institute of Applied Health Research, College of Medical and Dental Sciences, University of Birmingham, Edgbaston B15 2TT, UK.

E-mail: i.litchfieldabham.ac.uk

Submitted: 3 November 2015; Editor's response: 11 March 2016; final acceptance: 15 March 2016. (OBritish Journal of General Practice

This is the full-length article (published online 7 Jun 2016) of an abridged version published in print. Cite this version as: $\mathbf{B r} \mathbf{J}$ Gen Pract 2016; DOI: $10.3399 /$ bjgp 16 X685693 


\section{How this fits in}

Large numbers of patients are affected by hospital-acquired thrombosis. There is a clear need to improve current mechanisms for managing the issue. Primary care can fulfil this need, although currently its role is poorly defined and it remains underutilised. The authors conducted a series of semistructured interviews with primary care clinicians to explore perceptions of the current processes for preventing HAT across primary and secondary care. In doing so, ideas were gleaned on how the current management of HAT might be improved. Participants spoke of their limited role, both in educating patients and assessing the risk of HAT before admission, and the lack of contact with patients postdischarge. A number of reasons for this emerged, including a lack of clarity on the responsibility for patients, poor levels of communication, and, as a result, poor coordination of care between different settings. If a broader role for primary care is to be adopted, then there must be improved training for the relevant staff and the provision of appropriate resources.

Figure 1. Management of VTE risk in hospitalised patients (after NICE 2010). ${ }^{1}$ VTE = venous thromboembolism.

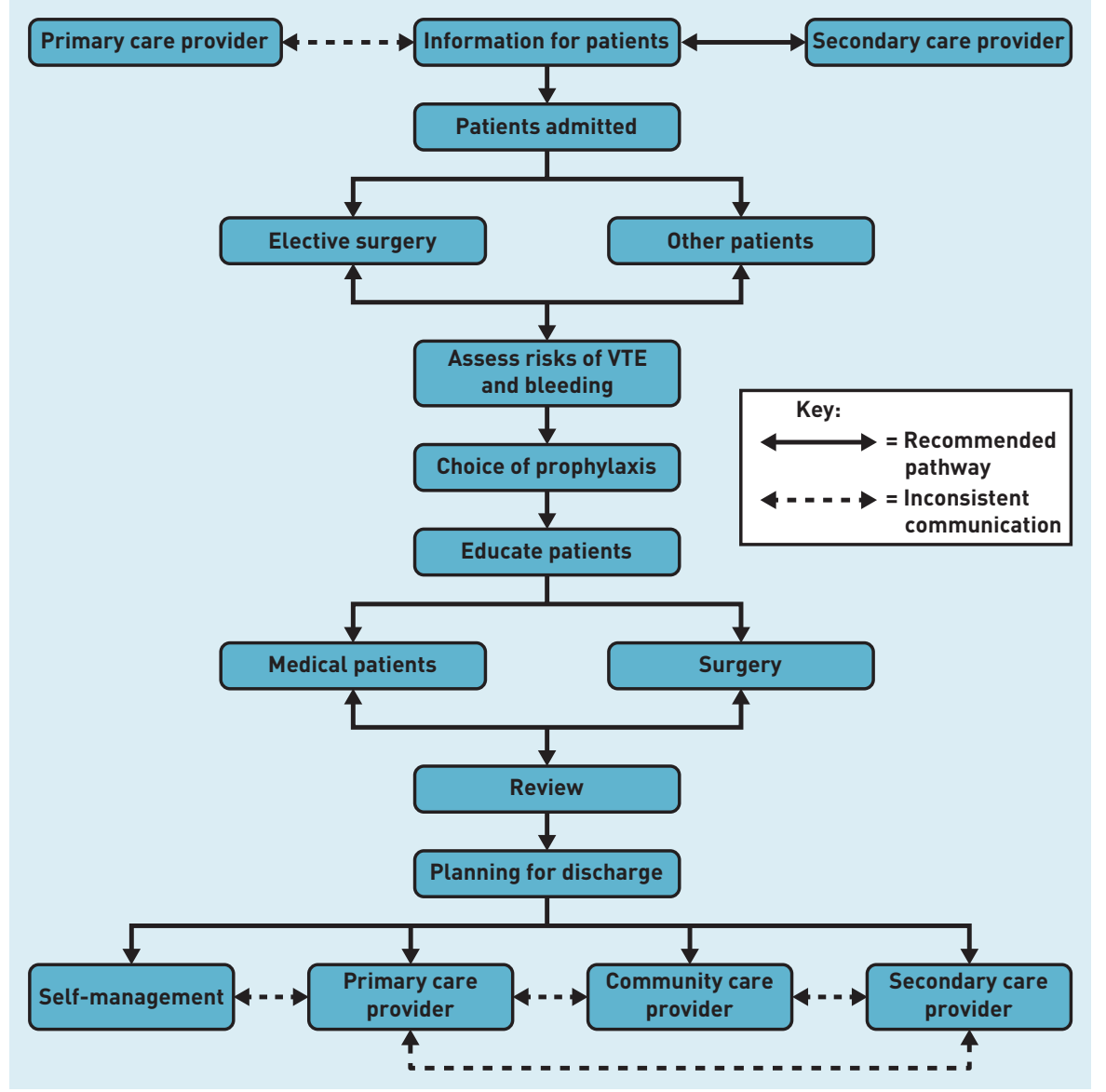

clinicians, and related staff in primary and secondary care, and other relevant organisations. ${ }^{30}$ Here the authors report on a qualitative exploration of the perspectives of primary care clinicians on the factors that influence HAT prevention, including potential barriers to improving current systems and how they may be overcome.

\section{METHOD}

The study sample was drawn from two former primary care trusts in Oxfordshire and South Birmingham. All 817 GPs and 583 practice nurses within the study area were sent a postal survey as part of the broader ExPeKT study and invited to participate in a semi-structured interview. From the 111 surveys that were returned, a total of 37 professionals confirmed they would be prepared to be interviewed. Following further contact by telephone, it was determined that, of these, three had retired and a further 20 were either unable to find a convenient time to take part or requested an online interview, which they failed to complete. A final total of 14 interviews took place: 12 GPs and two advanced nurse practitioners. Informed consent was obtained prior to conducting the interviews, which lasted between 10 and 50 minutes.

The study used semi-structured telephone interviews ${ }^{31}$ and a topic guide developed to explore clinicians' awareness of hospital-associated VTE, their perceptions of the awareness of patients, and the role of primary care in managing this problem, including any limiting factors and ways in which current systems of managing the issue might be improved (see Box 1 for topic guide). The interviews were conducted by a research fellow experienced in qualitative research, recorded using a telephone recording adaptor with a digital recorder, and transcribed verbatim.

\section{Analysis}

Each transcript was read and the findings analysed by two of the authors, who agreed on themes and decided upon the coding framework. Transcripts were analysed using a framework analysis. ${ }^{32}$

\section{RESULTS}

The sex of the participating clinicians are provided in Table 1, alongside a description of each practice, including the number of patients registered, Index of Multiple Deprivation ranking (IMD code), ${ }^{33}$ and an indication of rurality. ${ }^{34}$ The interviewed male and female GPs were from across eight practices. The practices were predominantly 


\section{Box 1. Topic guide for semi-structured telephone interviews}

- To what extent are GPs aware that hospital-acquired thrombosis (HAT) is a problem?

What is your awareness of existing guidelines?

- To what extent are patients aware of HAT?

Are there any characteristics of patients that affect this awareness?

Do they recognise symptoms?

- Where do you feel responsibility lies for preventing HAT?

- What is the role of primary care in managing HAT in the community?

Do you have contact with a patient either prior to admission or following discharge?

What are the factors that influence this patient contact?

- What are the factors that limit your role in managing HAT

- What is the level of contact with other care providers?

- What are the time and financial pressures?

- Have you received any training for HAT risk assessment and management?

- Do you feel that you receive adequate information from secondary care?

- How can the risk of HAT in the community be reduced?

- Can primary care play a useful role?

What can facilitate any change in role? and logistical constraints. In discussing suggestions for the way in which the risk of HAT might be reduced, ideas emerged within two key themes: either clinical innovation or organisational innovation. The key themes and associated subthemes are described in Box 2.

\section{Influences on HAT prevention in primary} care

GP awareness of HAT. The clinicians interviewed discussed their overall awareness of HAT and the nature of their specific role in its prevention. There appeared to be a general awareness of the risk of HAT to patients:

I'm aware that it's becoming a huge problem because I know that they screen everybody now, pretty much everybody has to be on prophylaxis.' (GP06)

I'm sure that the GPS are aware of it as a problem, yes.' (NPO2)

There appeared, however, little training specific to HAT other than that associated with the use of related medication:

I've probably not received official training along those lines, apart from warfarin, but no, no official training. '(GP01)

Nor were several of those interviewed aware of the existing guidelines for reducing the risk of HAT, including the risk factors that would require extended prophylaxis following discharge:

'There are hopefully protocols in place to prevent post-op VTE.' (GP02)

'Right now certainly I don't know which operations do and don't need extended prophylaxis.' (GP03)

Patient characteristics: clinical dependency and patient awareness. Clinicians described how clinical dependency and patient education would influence the level of involvement of primary care providers.

A patient whom the practice recognises as being particularly vulnerable would be reviewed either prior to admission or following discharge:

'We don't often see them unless either there's something that's flagged up in preop assessments, or if they've got particular concerns. I mean, we wouldn't routinely see someone, you know, before they go in for an operation.' (GP02) 


\section{Box 2. Themes and subthemes}

\begin{tabular}{|c|c|c|c|c|c|c|}
\hline \multicolumn{5}{|c|}{ Influences on hospital-acquired thrombosis prevention in primary care } & \multicolumn{2}{|c|}{$\begin{array}{l}\text { Suggestions for improving } \\
\text { current systems }\end{array}$} \\
\hline GP awareness & $\begin{array}{l}\text { Patient } \\
\text { characteristics }\end{array}$ & $\begin{array}{l}\text { Designation of } \\
\text { responsibility }\end{array}$ & $\begin{array}{l}\text { Coordination } \\
\text { of care }\end{array}$ & $\begin{array}{l}\text { Logistical } \\
\text { constraints }\end{array}$ & $\begin{array}{l}\text { Clinical } \\
\text { innovation }\end{array}$ & $\begin{array}{l}\text { Organisational } \\
\text { innovation }\end{array}$ \\
\hline $\begin{array}{l}\text { Current role } \\
\text { Training }\end{array}$ & $\begin{array}{l}\text { Awareness } \\
\text { Clinical dependency }\end{array}$ & $\begin{array}{l}\text { Secondary care } \\
\text { Primary care }\end{array}$ & $\begin{array}{l}\text { Communication } \\
\text { with primary care } \\
\text { and secondary care }\end{array}$ & $\begin{array}{l}\text { Pre-admission } \\
\text { risk assessment }\end{array}$ & $\begin{array}{l}\text { Oral-based } \\
\text { medication }\end{array}$ & $\begin{array}{l}\text { Improved } \\
\text { auditing }\end{array}$ \\
\hline & & & $\begin{array}{l}\text { Communication } \\
\text { with primary care } \\
\text { and community care }\end{array}$ & $\begin{array}{l}\text { Increasing patient } \\
\text { awareness } \\
\text { Post-discharge } \\
\text { appointments }\end{array}$ & $\begin{array}{l}\text { Software-based } \\
\text { clinical support } \\
\text { tool }\end{array}$ & $\begin{array}{l}\text { Increased role } \\
\text { of primary } \\
\text { care } \\
\text { Unified } \\
\text { commissioning }\end{array}$ \\
\hline
\end{tabular}

I think people who've had a prolonged admission or people who have multiple comorbidity or who are generally quite frail, you know, we might go and do a review post-discharge, particularly people on the Gold Standards Framework.' (GP02)

Where patients were vulnerable, GPs would either administer prophylaxis or otherwise enlist the support of district nurses:

Yes, we're more than happy to give that [Clexane ${ }^{\circledR}$ ] out to our patients - those patients who are elderly and are unable to administer it.' (GP01)

We get involved sometimes in arranging district nurses to administer extended courses of antithrombotics but it is very limited at the moment.' (GP09)

We also get our district nurses to go out and give them their Clexane injections.' (GP01)

The GPs described how some of the patients were vaguely aware of the issue, but not to the extent that they would recognise the symptoms:

'I think they're well aware that DVT involves getting a clot in your leg somewhere. I don't think they're too clued up about what the true symptoms are.' (GP01)

None of those interviewed felt that the patients were appropriately informed. Some questioned the effectiveness of the communication of educational information:

'I don't think they're educated when they go into hospital.' (GP03)

'They will always pretend that nobody has said anything, because they don't understand a lot of it. They say, "Oh no, nobody's ever said anything to me", and you know right well they have. They often say, "I haven't been told anything", because they just don't understand what's being said.' (NP01)

Designation of responsibility. Opinions varied on where responsibility for various aspects of HAT prevention should lie.

In considering educating patients, it was felt that the consultant within secondary care should bear responsibility:

If a hospital consultant is tabling somebody for surgery that is risky for DVT; they should be the one that is counselling the patient about DVT.'(GP06)

There were various opinions on who was responsible for patients adhering to their HAT prophylaxis prescription:

A difficult one, I mean it's been initiated in hospital and it's prescribed in hospital, so I would guess in the current system, it would have to be the hospital that was responsible.' (NP02)

I think once they've had their operation done, I think it's a grey area, in terms of where the responsibility lies. Does it lie with consultants who've done the operation to make sure that they've sent patients home with prophylaxis, or whether it's our job then to just make sure they are on prophylaxis when they come out?' (GP01)

Others believed that, following discharge, the responsibility automatically falls on primary care, based on the assumption that patients had previously received the appropriate information: 
'Once they're discharged on a 2-week course, it's obviously the GP's responsibility if they run into any problems. So as long as they've been advised what to look out for, then they would contact us if there are any problems.' (GP02)

Communication with primary care secondary care, and community care. GPs reported difficulties in coordinating care with colleagues in secondary and communitybased care, primarily as a result of poor communication.

This poor communication appeared to be an issue, both before admission and following discharge. Clinicians reported that, though they would generally receive notification of admission, the detail it contained could vary:

'Yes, we know they're going in invariably, if it's a planned admission ... sometimes we know the date, sometimes we don't know the date.' (GP08)

The inconsistent quality of the discharge summary was also reported, as was the lack of information the practice received relating to extended prophylaxis:

'That's completely pot luck. Some discharge summaries are very good, they tell you the dose of Clexane that they want you to give and for how many weeks and what they're treating for ... and then, on the other hand, you just don't really get any feedback at all. (GP01)

Another GP also noted the lack of precise information on extended prophylaxis:

Some of my patients have had, for example, a hip replacement and have had 35 days of injections; unless the patient tells you, you are not necessarily aware they are still taking it.' (GP09)

One GP attributed the variation in the quality of the discharge summary to the inexperience of the author:

Well the problem is the hospital discharge notes are written by very junior staff, they're writing them and they probably didn't know what they were writing it for.' (GPO3)

One of the GPs interviewed reported the problems of liaising with district nurses over the care of discharged patients:

'The district nurse still comes in [but] it's completely fragmented now. District nurses don't work with you any more, they are in a separate team. They are employed by the hospitals now and communication is extremely poor.' (GP09)

Logistical constraints. Several of the GPs interviewed described how the pressure on resources in primary care precluded increased involvement in preventing HAT:

'It's not part of the core services of a GP and one can't keep taking on sort of secondary care work without a funding stream.' (GP08)

Another GP described how current demands on their time meant they were unwilling to assume responsibility for educating patients about the risks of HAT:

At the moment we are seriously swamped with other work we've already got from the hospital and it would need a nurse's appointment for every patient going into hospital. So we would have to see them specifically to do this and so we absolutely, totally don't want to take it on.' (GP06)

There were also concerns voiced over the amount of time it would take to visit immobile patients following discharge:

It would require a lot of time ... the patients don't want to come in to the GP surgery when they've just had an operation so you're talking about sending doctors out to people's homes to go and talk to them about injecting low molecular weight heparin and preventing VTE.' (GP02)

\section{Suggestions for improvement}

The suggestions for improvement can be placed in one of two groups. The first, organisational innovations, consists of improved auditing, an increased and appropriately funded role for primary care, and unified commissioning of HAT.

The second group can be considered clinical innovations, namely clinical support tools and orally administered medication.

Improved auditing. One GP suggested that an important step was the systematic gathering of information on the time and cost issues of mismanaging HAT as a way of raising awareness and encouraging the appropriate investment:

I guess probably looking at the time and cost issues and putting that in front of the healthcare professionals and saying: "Look, this is something worthwhile doing because it does have financial and health costs if we don't do it."'(GP01) 
Increased role of primary care. It was acknowledged that an increased role for primary care could see benefits in a number of areas, including increased patient awareness and better coordination of care between primary and secondary care settings:

'Raising awareness of patients with planned admissions - that they ought to raise this issue [HAT] with the treating hospital - that would make a lot of sense. (GP09)

GPs also felt that they could take a more proactive role in communicating with consultants following major surgery:

I think we as GPS should question discharges a bit more, especially after big operations. I think, at the moment, we do leave it in the hands of the consultants. (GP01)

The greater involvement of staff would require improved training of relevant staff:

'Training, I think, would be good generally across all staff members, nurses, and doctors.' (GP01)

Unified commissioning. It was also suggested that the commissioning could be unified and provision of prophylaxis should become the responsibility of a single organisation:

I would definitely commission the whole lot, not a week here and the rest prescribed by someone else.' (GP09)

Clinical support tools. Software-based tools were mentioned as a means of supporting GPs to undertake any risk assessment:

Something like NHS Improvement should pick this up. Getting a risk assessment tool, a software tool, would be quite useful." (GP09)

Oral medication. Others felt that a more easily-administered medication would prove significant, reducing the need for clinician-mediated administration:

I mean, I'm looking forward to the time when oral anticoagulation will come and I know that that is available.' (NP02)

\section{DISCUSSION}

\section{Summary}

Despite having the opportunity to actively reduce the occurrence of HAT, the current role of GPs and, more broadly, primary care, appears limited, whether in educating patients and assessing risk of HAT prior to admission, or in the management of patients on prophylaxis following discharge. The clinicians interviewed described a number of factors that influence prevention of HAT in primary care. These included limited awareness among GPs and poor coordination of care with colleagues in community or secondary care settings, exacerbated by a lack of clarity concerning their role and frequent inconsistencies in the quality and timing of communication between care settings.

A number of constructive suggestions did emerge to improve the current system, and there was a broad consensus that there was opportunity for an increased role for primary care both pre-admission and post-discharge. Those interviewed were equally clear that due to current logistical constraints, any extended role for primary care would require additional and targeted funding.

\section{Strengths and limitations}

There is a growing understanding of the importance of managing HAT, though this is the first study to gain the perspectives of primary care providers. It cannot be commented on as to how representative these views are of the wider GP population; however, the practices represented a wide variety of IMD codes, list sizes, and geographical locations. Although telephone interviews were chosen over face-to-face interviews for practical reasons, short telephone interviews have been found to be equally as productive as short face-to-face interviews. ${ }^{35}$

Theoretical saturation was reached within the 14 interviews. ${ }^{36}$ The authors suggest that this comparatively small number could be explained by 'consensus theory', where 'experts' with shared knowledge about the topic under discussion are more likely to exhibit common values. ${ }^{37}$ The fact that so many GPs were too busy to be interviewed also supports the finding that the current demand for GP services limits the time available for undertaking additional activities.

\section{Comparison with existing literature}

Patients were reported as being neither aware of the risk of HAT, nor how it might best be managed following discharge, despite recommendations to the contrary.11 Previous work indicates that appropriate patient education can improve outcomes and adherence to medication. 16,38,39 Tools, 
such as enhanced medication plans, can improve information transfer and increase patient knowledge of individual drug treatment. ${ }^{40}$

The GPs interviewed also felt that this information might be better provided within the primary care environment. In hospital, patients can be flooded with information from doctors, frequently beyond their capacity to assimilate and memorise it, ${ }^{4}$ and, with shorter lengths of stay, ward staff are finding it harder to assess and meet the information needs of the patients, ${ }^{42}$ further inhibited by the complexity of the modern healthcare team. ${ }^{43}$ It has previously been suggested that greater responsibility for patient education should lie with primary care, ${ }^{44}$ where the quiet surroundings, ${ }^{45}$ managerial support, ${ }^{46,47}$ and the allocation of undisturbed time ${ }^{44}$ can facilitate improved communication.

Improving the coordination of HAT prevention between care settings would appear critical, considering the trend towards shorter hospital stays and increased delivery of care in the community. ${ }^{48-51}$ The coordination of care is key considering previous evidence of patients unprepared for their self-management role, ${ }^{19}$ and vulnerable to adverse events following discharge. ${ }^{24-29}$ However, the clinicians interviewed reported that any coordination was hindered by the fragmentation of their relationship with community care, and issues with the timeliness and content of the information they received from secondary care.

Of particular concern to many of the GPs interviewed was the quality of the discharge summary. These should be timely and contain information on newly prescribed medication or specific follow-up needs. ${ }^{11,29}$ However, many of the interviewed clinicians described them as late and frequently incomplete, reflecting previous evidence of GPs not routinely notified about patient admissions, discharges, or complications during the course of the hospital stay, ${ }^{52-}$ 55 and patients unable to access an appropriate healthcare practitioner in possession of their discharge summary. ${ }^{20-22}$ It was noted that summaries received from junior doctors were often poor, echoing previous research, which reported that junior doctors felt inadequately prepared for writing discharge summaries and needed improved training in the area. ${ }^{56}$ More robust systems of communication ${ }^{57,58}$ and increased involvement of informatics might benefit the production and dissemination of discharge summaries; both of these strategies have proven successful in other 'high-risk' circumstances. ${ }^{59}$ Another important aspect of the successful transition of patients is the mutually agreed transfer of responsibility from hospital to primary care provider; ${ }^{29}$ however, those interviewed offered conflicting opinions of where this responsibility should lie.

The National Institute for Health and Care Excellence (NICE) guidance is explicit in its recommendation for prompt and accurate communication with GPs, yet it would appear that this is not routinely followed. Though strategies have emerged that address HAT-specific barriers, such as continued education of junior doctors and giving greater prominence to medicated stockings on prescription charts, ${ }^{60,61}$ the means by which communication with primary care can be improved has yet to be explored.

It was acknowledged that primary care could support HAT prevention but it became clear that this was unlikely to happen without additional resources being available. Other suggestions to support the extended role for primary care advocated by some of those interviewed, such as improved training or the introduction of software-based clinical support, all have cost implications for an already stretched service. ${ }^{62}$ It was suggested that, in order to secure these funds, empirical evidence of the impact of HAT would help raise awareness of the issue and the financial implications of its mismanagement. In the absence of increased funding, the option remains to use existing resources more effectively. Recently, the use of pre-admission healthcare data has been successful in identifying high-risk cases of HAT, ${ }^{63}$ and it may be in the interim that this approach could help focus resources more precisely.

\section{Implications for practice}

The number of patients with HAT is high and onset frequently occurs post-discharge. Despite this, the level of awareness among GPs varied and many of those interviewed agreed that improved training of GPs and other relevant staff is needed. With that in place, primary care staff would be better equipped to raise awareness of HAT in patients, undertake a potentially better informed risk assessment, and support vulnerable groups in adherence to the prescribed thromboprophylaxis.

There appeared to be a lack of clarity of what was expected from primary care. This included confusion about where the responsibility for preventing HAT lay, and when and how primary care providers 
might be involved. An improved definition of the role of primary care would be useful and is reliant on the provision of the appropriate training.

This better-defined role for primary care should be predicated on prompt and accurate communication of patient information between primary and secondary care. Currently, GPs reported reliance on second-hand information from patients. With access to the appropriate information, those patients at most risk from HAT can be more closely monitored and supported by GPs. Previous work has demonstrated the positive impact of a simple educational intervention for raising patient awareness on prophylaxis adherence following urology surgery. ${ }^{18}$ Piloting a similar intervention across a range of sites, involving a broader range of at-risk patient groups, should be considered.

There appears to be a useful role for primary care in the prevention of HAT. Gathering evidence of the impact of mismanaging HAT may encourage policymakers and commissioning bodies to prioritise the issue and provide the additional resources that would be required. 


\section{REFERENCES}

1. Beasley JW, Wetterneck TB, Temte J, et al. Information chaos in primary care: implications for physician performance and patient safety. J Am Board Fam Med 2011; 24(6): 745-751

2. Geerts W, Pineo G, Heit J, et al. Prevention of venous thromboembolism: the Seventh ACCP Conference on Antithrombotic and Thrombolytic Therapy. Chest 2004; 126(3 suppl): 338S-400S.

3. Cohen AT, Agnelli G, Anderson FA, et al. Venous thromboembolism (VTE) in Europe. The number of VTE events and associated morbidity and mortality. Thromb Haemost 2007; 98(4): 756-764.

4. Health and Social Care Information Centre. Hospital episode statistics: admitted patient care, England - 2014-15. 2015. http://www.hscic.gov.uk/catalogue/ PUB19124/hosp-epis-stat-admi-summ-rep-2014-15-rep.pdf laccessed 16 May 2016).

5. Lester W, Freemantle N, Begaj I, et al. Fatal venous thromboembolism associated with hospital admission: a cohort study to assess the impact of a national risk assessment target. Heart 2013; 99(23): 1734-1739.

6. McRae S, Tran H, Schulman S, et al. Effect of patient's sex on risk of recurrent venous thromboembolism: a meta-analysis. Lancet 2006; 368(9533): 371-378.

7. Bouras G, Burns EM, Howell AM, et al. Risk of post-discharge venous thromboembolism and associated mortality in general surgery: a populationbased cohort study using linked hospital and primary care data in England. PLoS One 2015; 10(12): e0145759.

8. Bergmann JF, Cohen AT, Tapson VF, et al. Venous thromboembolism risk and prophylaxis in hospitalised medically ill patients. The ENDORSE Global Survey. Thromb Haemost 2010; 103(4): 736-748.

9. Bozzato S, Galli L, Ageno W. Thromboprophylaxis in surgical and medical patients. Semin Respir Crit Care Med 2012; 33(2): 163-175.

10. Khanna R, Maynard G, Sadeghi B, et al. Incidence of hospital-acquired venous thromboembolic codes in medical patients hospitalized in academic medical centers. J Hosp Med 2014: 9(4): 221-225.

11. National Institute for Health and Care Excellence. Venous thromboembolism: reducing the risk for patients in hospital. CG92. London: NICE, 2010, https:// uww.nice.org.uk/guidance/cg92 laccessed 12 May 2016).

12. Department of Health. Venous thromboembolism (VTE) risk assessment. 2010. http://webarchive.nationalarchives.gov.uk/20130107105354/http:/www.dh.gov. uk/en/Publicationsandstatistics/Publications/PublicationsPolicyAndGuidance/ DH 088215 (accessed 12 May 2016).

13. Collins R, Scrimgeour A, Yusuf S, Peto R. Reduction in fatal pulmonary embolism and venous thrombosis by perioperative administration of subcutaneous heparin. Overview of results of randomized trials in general, orthopedic, and urological surgery. N Engl J Med 1988; 318(18): 1162-1173.

14. Friedman RJ, Gallus AS, Cushner FD, et al. Physician compliance with guidelines for deep-vein thrombosis prevention in total hip and knee arthroplasty. Curr Med Res Opin 2008; 24(1): 87-97.

15. Wilke T, Müller S. Nonadherence in outpatient thromboprophylaxis after major orthopaedic surgery: a systematic review. Expert Rev Pharmacoecon Outcomes Res 2010; 10(6): 691-700.

16. Wilke T, Moock J, Müller S, et al. Nonadherence in outpatient thrombosis prophylaxis with low molecular weight heparins after major orthopaedic surgery. Clin Orthop Relat Res 2010; 468(9): 2437-2453.

17. Wade R, Sideris E, Paton F, et al. Graduated compression stockings for the prevention of deep-vein thrombosis in postoperative surgical patients: a systematic review and economic model with a value of information analysis. Health Technol Assess 2015; 19(98): 1-220.

18. Hardy TJ, Upchurch E, Duff H, Davenport K. Post-operative use of low molecular weight heparin: are patients doing their bit? J Clin Urol 2016; 9(3): 162-165.

19. Coleman E, Parry C, Chalmers S, Min S. The care transitions intervention: results of a randomized controlled trial. Arch Intern Med 2006; 166(17): 18221828

20. Levine C. Rough crossings: family caregivers' odysseys through the health care system. New York: United Hospital Fund of New York, 1998.

21. vom Eigen KA, Walker JD, Edgman-Levitan S, et al. Carepartner experiences with hospital care. Med Care 1999; 37(1): 33-38.

22. Weaver FM, Perloff $L$, Waters T. Patients' and caregivers' transition from hospital to home: needs and recommendations. Home Health Care Serv Q 1998; 17(3): 27-48
23. Dudas V, Bookwalter T, Kerr KM, Pantilat SZ. The impact of follow-up telephone calls to patients after hospitalisation. Am J Med 2001; 111(9B) 26S-30S.

24. Kautz CM, Gittell JH, Weinberg DB, et al. Patient benefits from participating in an integrated delivery system: impact on coordination of care. Health Care Manage Rev 2007; 32(3): 284-294.

25. Beers M, Sliwkowski J, Brooks J. Compliance with medication orders among the elderly after hospital discharge. Hosp Formul 1999; 27(7): 720-724.

26. Coleman EA, Smith JD, Raha D, Min SJ. Posthospital medication discrepancies: prevalence and contributing factors. Arch Intern Med 2005; 165(16): 1842-1847.

27. Cornish PL, Knowles SR, Marchesano R, et al. Unintended medication discrepancies at the time of hospital admission. Arch Intern Med 2005; 165(4): 424-429.

28. Moore C, Wisnivesky J, Williams S, McGinn T. Medical errors related to discontinuity of care from an inpatient to outpatient setting. J Gen Intern Med 2003; 18(8): 646-651.

29. Kripalani S, LeFevre F, Phillips CO, et al. Deficits in communication and information transfer between hospital-based and primary care physicians: implications for patient safety and continuity of care. JAMA 2007; 297(8): 831-841

30. McFarland L, Ward A, Greenfield S, et al. ExPeKT - exploring prevention and knowledge of venous thromboembolism: a two-stage, mixed-method study protocol. BMJ Open 2013; 3(4): e002766.

31. Gill P, Stewart K, Treasure E, Chadwick B. Methods of data collection in qualitative research: interviews and focus groups. Br Dent J 2008; 204(6): 291-295.

32. Gale NK, Heath G, Cameron $E$, et al. Using the framework method for the analysis of qualitative data in multi-disciplinary health research. BMC Med Res Methodol 2013; 13: 117.

33. McLennan D, Barnes $\mathrm{H}$, Noble $\mathrm{M}$, et al. The English indices of deprivation 2010. London: Department for Communities and Local Government, 2011. https://www.gov.uk/government/uploads/system/uploads/attachment_data/ file/6320/1870718.pdf (accessed 16 May 2016).

34. Department of Environment, Food \& Rural Affairs. 2011 Rural Urban Classification. https://uww.gov.uk/government/publications/2011-rural-urbanclassification (accessed 12 May 2016).

35. Sturges JE, Hanrahan KJ. Comparing telephone and face-to-face qualitative interviewing: a research note. Qual Res 2004; 4: 107-118.

36. Morse JM. Biased reflections: principles of sampling and analysis in qualitative inquiry. In: Popay J, ed. Moving beyond effectiveness in evidence synthesis: Methodological issues in the synthesis of diverse sources of evidence. London: NICE, 2006: 53-60

37. Romney AK, Weller SC, Batchelder WH. Culture as consensus: a theory of culture and informant accuracy. Am Anthropol 1986; 88(2): 313-338.

38. Street RL Jr, O'Malley KJ, Cooper LA, Haidet P. Understanding concordance in patient-physician relationships: personal and ethnic dimensions of shared identity. Ann Fam Med 2008; 6(3): 198-205.

39. Colwell Jr CW. Pulido P. Hardwick ME. Patient compliance with outpatient prophylaxis: an observational study. Orthopedics 2005; 28(2): 143-147.

40. Send AF, Schwab M, Gauss A, et al. Pilot study to assess the influence of an enhanced medication plan on patient knowledge at hospital discharge. Eur J Clin Pharmacol 2014: 70(12): 43-50.

41. Kripalani S, Jacobson TA, Mugalla IC, et al. Health literacy and the quality of physician-patient communication during hospitalization. J Hosp Med 2010; 5(5): 269-275.

42. Barber-Parker ED. Integrating patient teaching into bedside patient care: a participant-observation study of hospital nurses. Patient Educ Couns 2002; 48(2): 107-113.

43. Worth A, Tierney AJ, Watson NT. Discharged from hospital: should more responsibility for meeting patients' and carers' information needs now by shouldered in the community? Health Soc Care Community 2000; 8(6): 398-405.

44. Bergh AL, Karlsson J, Persson E, Friberg F. Registered nurses' perceptions of conditions for patient education - focusing on organisational, environmental and professional cooperation aspects. J Nurs Manag 2012; 20(6): 758-770.

45. Lipponen K, Kyngäs H, Kääriäinen M. Surgical nurses readiness for patient counselling. J Orthop Nurs 2006; 10: 221-227.

46. Turner D, Wellard S, Bethune E. Registered nurses' perceptions of teaching: constraints to the teaching moment. Int J Nurs Pract 1999; 5(1): 14-20.

47. Moret L, Rochedreux A, Chevalier S, et al. Medical information delivered to 
patients: discrepancies concerning roles as perceived by physicians and nurses set against patient satisfaction. Patient Educ Couns 2008; 70(1): 94-101.

48. Clare J, Hofmeyer A. Discharge planning and continuity of care for aged people: indicators of satisfaction and implications for practice. Aust J Adv Nurs 1998; 16(1): 7-13.

49. Mckeown F. The experiences of older people on discharge from hospital following assessment by the public health nurse. J Clin Nurs 2007; 16(3): 469-476.

50. Mistiaen P. Duijnhouwer E, Wijkel D, et al. The problems of elderly people at home one week after discharge from an acute care setting. J Adv Nurs 1997 25(6): 1233-1240

51. Coleman EA. Falling through the cracks: challenges and opportunities for improving transitional care for persons with continuous complex care needs. $J$ Am Geriatr Soc 2003; 51(4): 549-555.

52. Mclnnes E, Mira M, Atkin N, et al. Can GP input into discharge planning result in better outcomes for the frail aged: results from a randomized controlled trial. Fam Pract 1999; 16(3): 289-293.

53. Rutherford A, Burge B. General practitioners and hospitals: continuity of care. Aust Fam Physician 2001; 30(11): 1101-1107.

54. Wachter RM, Pantialt SZ. The 'continuity visit' and the hospitalist model of care. Am J Med 2001; 111(9B): 40-42.

55. Pantilat SZ, Lindenauer PK, Katz PP, Wachter RM. Primary care physician attitudes regarding communication with hospitalists. Am J Med 2001 111(9B): 15S-20S.
56. Yemm R, Bhattacharya D, Wright D, Poland F. What constitutes a high quality discharge summary? A comparison between the views of secondary and primary care doctors. Int J Med Educ 2014; 5: 125-131.

57. Risser DT, Rice MM, Salisbury ML, et al. The potential for improved teamwork to reduce medical errors in the emergency department. The MedTeams Research Consortium. Ann Emerg Med 1999; 34(3): 373-383.

58. Davenport DL, Henderson WG, Mosca CL, et al. Risk-adjusted morbidity in teaching hospitals correlates with reported levels of communication and collaboration on surgical terms but not with scale measures of teamwork climate, safety climate, or working conditions. J Am Coll Surg 2007; 205(6): 778-784.

59. Archie RR, Boren SA. Opportunities for informatics to improve discharge planning: a systematic review of the literature. AMIA Annu Symp Proc 2009; 2009: 16-20.

60. Aung M, Vaughan-Shaw P, Hutton J, Borley N. Adherence to VTE guidelines on surgical wards. Br J Surg 2015; 102(Suppl.1): 2

61. Cunningham R, Murray A, Byrne J, et al. Venous thromboembolism prophylaxis guideline compliance: a pilot study of augmented medication charts. Ir J Med Sci2015; 1842(2: 469-474.

62. NHS Confederation. Tough times, tough choices: being open and honest about NHS finance. Report number: BOK60063. London, NHS Confederation, 2013.

63. Zhang Z, Shen B, Yang J, et al. Risk factors for venous thromboembolism of total hip arthroplasty and total knee arthroplasty: a systematic review of evidences in ten years. BMC Musculoskelet Disord 2015; DOI: 10.1186/s12891015-0470-0 